УДК 622.349 .18

\title{
The Way of Transportation \\ of the Solid Natural Resources \\ to the Water Area Surface of the Arctic Shelf
}

Victor E. Kislyakov, Dmitry A. Lakin* and Irina A. Baranova

Siberian Federal University

79 Svobodny, Krasnoyarsk, 660041, Russia

Received 06.03.2015, received in revised form 08.07.2015, accepted 22.10.2016

The article considers the modern state and prospects of non-cohesive natural resources development of the continental shelf of Russia and proposes the technological solutions in the area of natural resources mining and transportation from the underwater stall making it possible to minimize the ecological damage from production. The authors have developed the mathematical model describing the process of the natural resources lifting from the underwater stall to the water area surface with external factors influence account.

Keywords: the Arctic shelf, underwater stall, technology, natural resources mining, frazil ice, heatmass- exchange, hydrodynamics.

Citation: Kislyakov V.E., Lakin D.A., Baranova I.A. The way of transportation of the solid natural resources to the water area surface of the arctic shelf, J. Sib. Fed. Univ. Eng. technol., 2016, 9(1), 133-140. DOI: 10.17516/1999-494X-2016-9-1-133-140.

\section{Способ транспортирования}

твёрдых полезных ископаемых

на поверхность акватории арктического шельфа

\author{
В.Е. Кисляков, Д.А. Лакин, И.А. Баранова \\ Сибирский федеральный университет \\ Россия, 660041, Красноярск, Свободный, 79
}

Рассмотрены современное состояние и перспективы освоения подводных месторождений несвязных полезных ископаемых континентального шельфа России, предложены технологические решения в области добычи и транспортирования полезного ископаемого из подводного забоя, позволяющче минимизировать экологический ущерб от проведения

(C) Siberian Federal University. All rights reserved

* Corresponding author E-mail address: d_099@mail.ru 
добычных работ. Разработана математическая модель, описывающая процесс подъёма полезного ископаемого из подводного забоя на поверхность акватории с учётом влияния внешних факторов.

Ключевые слова: арктический шельф, подводный забой, технология, выемка полезного ископаемого, внутриводный лёд, экология, тепломассообмен, гидродинамика.

Арктический шельф России является наиболее перспективным направлением в части восполнения запасов полезных ископаемых, значительную часть из которых занимают месторождения несвязных горных пород (золото, олово, платина, алмазы, хромит, минералы титана, железа, циркония и редких земель). К примеру, в арктической шельфовой области известны шесть оловоносных районов с месторождениями и их группами в россыпных узлах. При этом значительная доля запасов (64 \%) и прогнозных ресурсов $\mathrm{P}_{1}(98 \%)$ и $\mathrm{P}_{2}(86 \%)$ приходится на подводные россыпи. Перспектива истощения запасов минеральных ресурсов на материковой части предопределяет переориентацию разведки и добычи ресурсов полезных ископаемых на континентальный шельф. Большие объемы (около 370 тыс. т) олова приходятся на прогнозные ресурсы категории $\mathrm{P}_{3}$. В целом ресурсы олова в шельфовых областях России сопоставимы с его запасами в крупных оловоносных провинциях континентальной части страны. Анализируя соотношение запасов олова известных и прогнозируемых за счет категорий $\mathrm{P}_{1}, \mathrm{P}_{2}$ и $\mathrm{P}_{3}$, можно предположить, что их прирост в ближайшей перспективе может составить только по арктическим областям около 40 \% (около 90 тыс. т), а также в отдаленном будущем для всех шельфов России еще около 100 тыс. т (по данным В.Д. Каминского, О.И. Супруненко, А.Н. Смирнова, ФГУП ВНИИ Океангеология им. И.С. Грамберга). Несмотря на очевидные перспективы освоения, общая изученность российского шельфа продолжает оставаться низкой.

Следует иметь в виду, что все существующие на данный момент способы добычи полезных ископаемых со дна морей и океанов малоэффективны в суровых условиях арктической зоны России, требуют больших затрат сил, энергии и денежных средств на их реализацию. Связано это с постоянной отрицательной температурой, обледенением добычного оборудования, которое влечёт за собой отказ устройств и простои добычных комплексов или отдельных выемочных единиц. Тяжелые условия ручного труда сводят на нет все попытки круглогодичной разработки месторождений.

Таблица 1. Буровая изученность континентального шельфа России

\begin{tabular}{|l|c|c|c|}
\hline \multicolumn{1}{|c|}{ Название } & $\begin{array}{c}\text { Количество } \\
\text { разведочных } \\
\text { скважин, шт }\end{array}$ & $\begin{array}{c}\text { Протяженность } \\
\text { полигона, } \\
\text { тыс. пог. км }\end{array}$ & $\begin{array}{c}\text { Плотность сети } \\
\text { скважин, км/км }\end{array}$ \\
\hline Баренцево и Печерское моря & 51 & 428.3 & 0.41 \\
\hline Карское море & 19 & 116.8 & 0.13 \\
\hline Море Лаптевых & - & 27.5 & 0.04 \\
\hline $\begin{array}{l}\text { Восточно-Сибирское и Чукотское } \\
\text { моря }\end{array}$ & - & $8.8 ; 13.3$ & $0.01 ; 03$ \\
\hline Берингово море & 1 & 69.1 & 0.1 \\
\hline Охотское и Японское моря & 90 & 433.2 & 0.22 \\
\hline
\end{tabular}


Не менее важным аспектом в отработке несвязных пород Арктической зоны является экологичность применяемых технологий в процессе выемки и транспортирования полезного ископаемого на поверхность.

Техногенное воздействие на океан производственной деятельности в течение последних десятилетий привело в отдельных регионах к серьёзным негативным последствиям, снижению природной способности морских экосистем к воспроизводству и саморегулированию.

Следует признать, что большинство действующих в наше время добычных технологий, применяемых при освоении морских месторождений, экологически несостоятельно. Предотвращение загрязнения окружающей среды при разработке подводного забоя станет возможным при создании технологических процессов, максимально приближенных к природным.

\section{Цели и причина исследования}

Актуальность исследований по изысканию новых адаптированных способов выемки и транспортирования несвязных пород в суровых климатических условиях обусловлена низкой эффективностью существующих технологий добычи полезных ископаемых. Внедрение инновационных способов позволит сократить время и финансовые затраты на добычу полезного ископаемого со дна континентального шельфа России, а также минимизировать экологический ущерб.

Сохранение экологического равновесия возможно прежде всего путём замкнутых и ресурсосберегающих технологий и производств. При разработке россыпей шельфа эта проблема может решаться в двух направлениях:

- разработка месторождений с придонным обогащением и возвратом хвостов обогащения в выработанное пространство россыпи;

- разработка с обогащением на поверхности или на береговых обогатительных фабриках.

Применение замкнутых технологий в арктических широтах нашей страны с оптимизацией всех вспомогательных и основных технологических процессов позволит минимизировать или совсем исключить облако мутности при разработке подводного забоя, в котором обычно превышены фоновые показатели твёрдых взвешенных частиц. Это также снизит степень воздействия большинства факторов, влияющих на нарушение экологической обстановки, таких как фракционный состав разрабатываемых горных пород, их гидравлическая крупность, способность к коагуляции, коэффициент пористости, количество мелкой фракции, способной переходить во взвесь, содержание твёрдой фазы в пульпе и др.

Замкнутая технология даст возможность избежать замутнения водной среды в процессе подготовки горной массы к выемке в подводном забое, при транспортировании её на поверхность акватории и при возврате хвостов обогащения обратно в выработанное пространство. Возврат хвостов уменьшит ущерб от изменения профиля и конфигурации площади морского дна, минимизирует образование подводных выемок (карьеров, траншей, воронок) и подводных насыпей - отвалов [1].

С учётом всех факторов и особенностей, влияющих на отработку несвязных пород морских месторождений арктической зоны России, была предложена технология их добычи и транспортирования [2], которая может быть использована для добычи полезного ископаемого 
как на материковых обводнённых месторождениях в зимний период, так и на месторождениях континентального шельфа России. Следует отметить, что выемка полезного ископаемого производится с ледовой поверхности, образующейся на водоёмах в период наступления холодов. Характерное отличие разработанной технологии от существующих заключается в использовании отрицательной температуры окружающей среды. Холодный воздух играет роль хладагента, необходимого для успешного осуществления технологических процессов в подводном забое. Предлагаемая технология позволяет использовать основной недостаток арктических территорий - лёд и отрицательную температуру - как основу для успешного осуществления выемки и транспортирования несвязных пород из подводного забоя на поверхность акватории. Выемка и транспортирование полезного ископаемого из подводного забоя основывается на природном процессе образования внутриводных льдов и разности плотности льда и воды (лёд без микроскопических пор и трещин имеет плотность 0,9168 г $/ \mathrm{cm}^{3}$ при $0{ }^{\circ} \mathrm{C}$, а вода при той

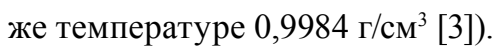

Благодаря разности плотности льда и воды, образовавшийся у дна лёд всплывает на поверхность акватории. В ходе детального изучения процесса формирования льда было выявлено, что для успешного его образования в подводном забое необходимо создать некоторые благоприятные условия: наличие отрицательных температур и центров кристаллизации.

Центрами (ядрами) кристаллизации служат частички пыли и пузырьки воздуха. В случае же внедрения данного явления в технологический процесс ядрами кристаллизации вполне успешно могут оказаться мельчайшие частицы полезного ископаемого, взвешенные в толще подводного забоя, а катализатором к началу образования льда служит воздух с отрицательной температурой, который подаётся с поверхности Арктической акватории и выполняет одновременно роль барбатирующего и кристаллизующего вещества. Таким образом, формируется грунтоледовое тело (ГЛТ), пример образования которого приведён на рис. 1.

Процесс подъёма ГЛТ происходит спустя некоторое время после его образования в подводном забое; объясняется это тем, что ледовой части ГЛТ необходимо набрать достаточную

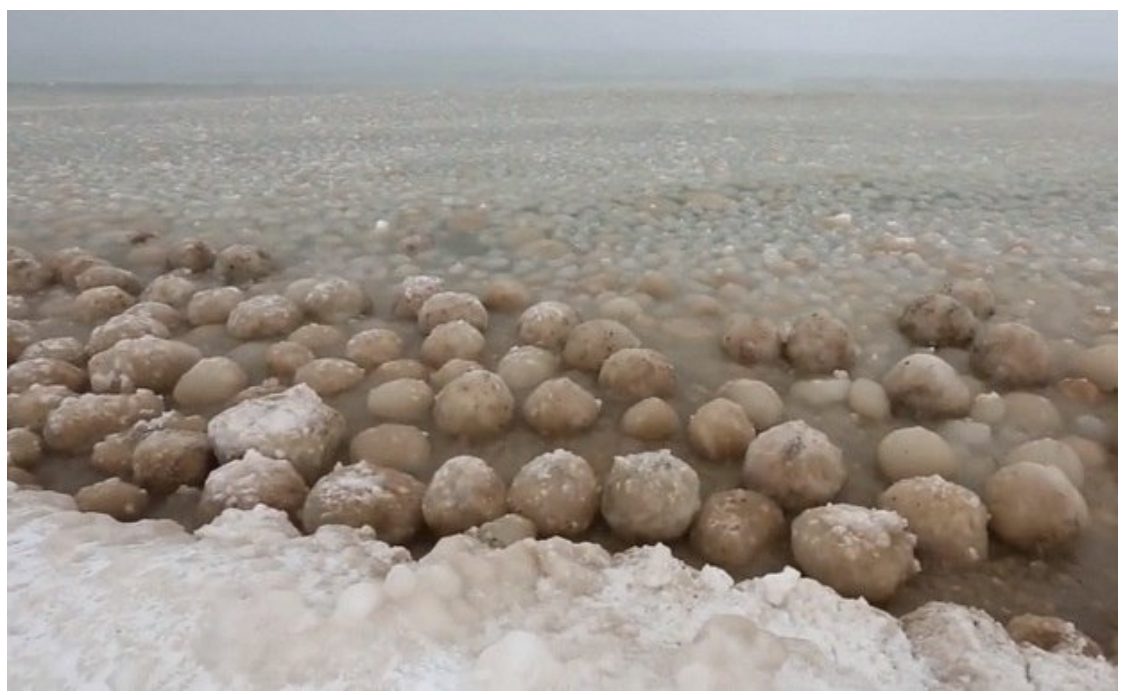

Рис. 1. Пример образования грунтоледового тела в природных условиях озера Мичиган (США) 
грузоподъёмность за счёт наросшего льда на частицу полезного ископаемого. Для этого в подводный забой постоянно подаётся воздух с отрицательной температурой - хладагент, который способствует образованию новых центров кристаллизации и завершению формирования уже существующих ГЛТ. После окончательного формирования ГЛТ всплывают на поверхность акватории.

Тела, образовавшиеся в подводном забое, представляют собой смесь частиц полезного ископаемого, льда и воздушных пор. Это объясняется тем, что в подводном забое намораживание льда на частицы полезного ископаемого протекает со скоростью более 2-3 мм/ч, при такой скорости замерзания выталкивание воздуха из кристаллической решетки льда идёт быстрее диффузии и на границе растущего льда формируется слой с повышенной концентрацией воздуха [4].

Количество воздуха, которое может раствориться в воде (растворимость), не беспредельно, поэтому через некоторое время после того, как начинается процесс замерзания, концентрация воздуха оказывается выше растворимости и создаётся перенасыщение. При наличии подходящего группирующего центра, в нашем случае частиц полезного ископаемого, молекулы воздуха постепенно собираются вместе и происходит образование воздушной поры.

Следует отметить, что ГЛТ, образовавшиеся в подводном забое, будут иметь воздушные поры, в зависимости от процентного содержания которых и плотности льда будет меняться подъёмная сила и скорость всплытия тел на поверхность акватории.

\section{Методика исследования}

Предлагаемая технология выемки и транспортирования несвязных полезных ископаемых основывается на законах Ньютона и не противоречит естественным процессам ледообразования.

В основу расчёта скорости подъёма положен второй закон Ньютона. Рассмотрим силы, действующие на тело в подводном забое:

- сила Архимеда $F_{a}=\rho_{ж} \cdot g \cdot V_{o}$, где $\rho_{ж}$ - плотность жидкости; $V_{o}$ - общий объём ГЛТ;

- сила тяжести $F_{m}=m g$, где $m$ - масса ГЛТ; $g$ - ускорение свободного падения;

- сила сопротивления по Рейнольдсу $F_{c}=\beta \cdot S \cdot \vartheta \cdot \rho_{\varkappa}$, где $\beta$ - безразмерный коэффициент, определяемый эмпирически.

Для того чтобы тело поднималось равномерно, необходимо соблюдение равенства сил $F_{c}=F_{a}-m g$. В этом случае скорость равномерного движения можно рассчитать по формуле

$$
\vartheta=\sqrt{\frac{4\left(F_{a}-m g\right)}{\beta \cdot \pi \cdot d^{2} \cdot \rho_{\varkappa}}},
$$

где $d$ - диаметр ГЛТ, м.

Масса ГЛТ

$$
m=m_{\Omega}+m_{6}+m_{2},
$$

где $m_{n}-$ масса льда, кг; $m_{s}-$ масса воздуха, кг; $m_{2}-$ масса грунта, кг. 
Масса льда

$$
m_{\Omega}=\rho_{\Omega} \cdot V_{\Omega}=\rho_{\pi 1} \cdot\left(V_{o}-V_{\beta}-V_{2}\right),
$$

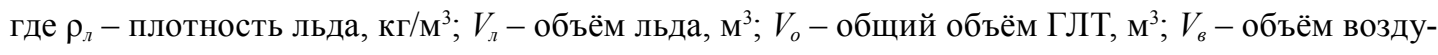
ха, м $^{3} ; V_{2}$ - объём грунта, м $^{3}$.

Масса воздуха, находящегося в пустотах льда,

$$
m_{B}=\rho_{B} \cdot V_{B}=\rho_{B} \cdot k \cdot V_{\pi},
$$

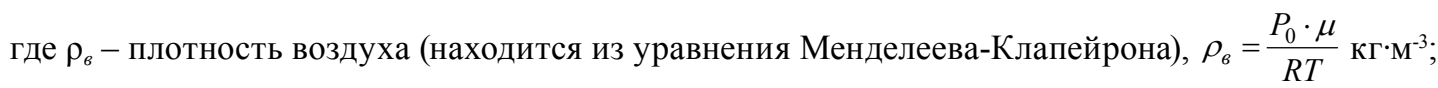

$P_{o}$ - давление, Па; $\mu$ - молярная масса, кг/моль; $R$ - универсальная газовая постоянная, Дж/(мольК); $T$ - абсолютная температура, К; $k$ - коэффициент пустот, зависит от скорости образования ГЛТ.

С учётом пустот и массы воздуха в нём общая масса ГЛТ составит

$$
m=\rho_{\Omega}(1-k) \cdot V+m_{2}+\rho_{B} \cdot k \cdot V=V \cdot\left(\rho_{\Omega} \cdot(1-k)+\rho_{B}\right)+m_{2} .
$$

Рассмотрим различные случаи подъёма ГЛТ.

1. При подъеме льда без грунта при условии, что тело поднимается равномерно $\left(m_{2}=0\right.$, $\left.V_{o}=V_{\pi}\right)$ :

$$
\vartheta=\sqrt{\frac{4 \cdot V_{o} \cdot g\left(\rho_{0}-\left(\rho_{\pi 1} \cdot(1-k)+\rho_{B} \cdot k\right)\right)}{\beta \cdot \pi \cdot d^{2} \cdot \rho_{0}}} .
$$

2. При подъеме ГЛТ с наличием грунта.

Масса ГЈIТ

$$
m=\rho_{\pi} \cdot V_{l}+m_{2}+\rho_{\theta} \cdot k \cdot V_{\pi}
$$

Объём льда

$$
V_{\pi}=\frac{m-m_{2}}{\rho_{\Omega}+\rho_{\theta} \cdot k}
$$

С учётом этого масса ГЛТ

$$
m=V \cdot\left(\rho_{\Omega}+\rho_{B} \cdot k\right)+m_{2} .
$$

Скорость подъёма ГЛТ с грунтом

$$
v=\sqrt{\frac{4 \cdot\left(F_{a}-m g\right)}{\beta \cdot \pi \cdot d^{2} \cdot \rho_{0}}}=\sqrt{\frac{4 \cdot\left(\rho_{0} \cdot g \cdot V_{o}-\left(V_{o}-m_{2} / \rho_{2}-V_{b}\right) \cdot\left(\rho_{n}+\rho_{b} \cdot k\right)+m_{2}\right) \cdot g}{\beta \cdot \pi \cdot d^{2} \cdot \rho_{0}}} .
$$

При равномерной скорости подъема ГЛТ с учётом процессов таяния и теплопроводности льда необходимо рассчитать величину его оттаиваемого слоя.

Вода обладает рядом уникальных свойств, например, при повышении давления температура плавления в отличие от большинства веществ понижается. Также в твердой фазе (лед) она обладает низкой теплопроводностью, поэтому количество энергии, передаваемой ГЛТ от 
внешней среды, идет на нагрев слоя толщиной $\Delta d$ и, соответственно, на его плавление, а не передается к центру.

Будем считать, что при подъёме на высоту, равную радиусу, скорость подъёма ГЛТ равномерна, тогда на основе теплового баланса получим формулу теплопроводности для расчёта толщины оттаиваемого слоя $\Delta d$.

Количество энергии, получаемое от внешней среды за счёт теплопроводности, идёт на нагрев слоя $\Delta d$ :

$$
Q_{1}=\chi \cdot \frac{\Delta T}{\Delta r} \cdot 4 \cdot \pi \cdot r^{2} \cdot \Delta t
$$

где $\chi$ - коэффициент теплопроводности льда, Вт/(м·К); $\Delta T / \Delta r$ - градиент температур вдоль оттаиваемого слоя $\Delta r ; \Delta t-$ время оттайки слоя $\Delta r$.

Количество тепла, требуемого на нагрев от температуры слоя до температуры плавления и собственно на плавление поверхностного слоя ГЛТ толщиной,

$$
Q_{2}=c \cdot \Delta m \cdot\left(T_{1}-T\right)+\lambda \cdot \Delta m
$$

где $c$ - теплоёмкость льда, Дж/кг; $T_{n л}$ - температура плавления льда $\mathrm{C}^{\circ} ; T$ - температура слоя воды, $\mathrm{C}^{\circ} ; \lambda$ - удельная теплота плавления льда, Дж/кг; $\Delta m$ - масса оттаиваемого слоя, кг.

Исходя из закона сохранения энергии $\mathrm{Q}_{1}=\mathrm{Q}_{2}$,

$$
\Delta d=2 \sqrt{\chi \frac{\left(T-T_{\partial}\right)}{\rho_{l}\left(c \cdot\left(T_{n l}-T\right)+\lambda\right)} \frac{r}{\vartheta}}=2 \sqrt{\chi \frac{\left(T-T_{\partial}\right)}{2 \rho_{l}\left(c \cdot\left(T_{n l}-T\right)+\lambda\right)} \frac{d}{\vartheta}},
$$

где $T$ - температура слоя воды на высоте подъёма Н при всплытии; $T_{\partial}$ - температура на дне акватории.

В нашем случае градиент температур равен $\operatorname{grad} T=\frac{\Delta T}{H}$, где $H-$ общая глубина разра-

ботки; $\Delta T=T_{o}-T_{\partial}-$ разность температур между температурой $T_{o}$ на поверхности акватории и температурой дна $T_{\partial}$.

Температуру слоя на высоте h высисляют по формуле

$$
T=T_{\partial}+\operatorname{grad} T \cdot h,
$$

где $h$ - некоторая высота, на которой находится ГЛТ в момент подъёма.

Поскольку температура оттайки зависит от давления на дне, то температура плавления на высоте h определяется по фазовой диаграмме воды.

Полученная модель позволит производить расчёт технологических параметров, таких как размер ГЛТ, формируемого в подводном забое, его подъёмную способность в зависимости от содержания в нём полезного ископаемого и воздушных пор, интенсивность оттайки в процессе всплытия ГЛТ при изменении температуры акватории по мере подъёма на поверхность, а также определить эффективную глубину отработки полезного ископаемого.

Предлагаемая технология выемки полезного ископаемого и его подъёма на поверхность максимально приближена к природным явлениям и основывается на процессах формирования 
внутриводного льда, тем самым сокращая или исключая экологический ущерб при отработке месторождения в подводном забое.

\section{Список литературы}

[1] Добрецов В.Б., Рогалев В.А. Основные вопросы освоения минеральных ресурсов Мирового океана. СПб.: МАНЭБ, 2003, 524 с. [Dobretsov V.B., Rogalev V.A. The main issues of development of the World ocean mineral resources, St. Petersburg, 2003, 524 p. (in Russian)]

[2] Kislyakov V.E., Korzun O.A., Lakin D.A. Russian geology and geophysics, 2010, 51.

[3] Лёд и другие состояния воды [Электронный ресурс] [Ice and other water conditions], available at: http://www.o8ode.ru/article/answer/ice/bestice.htm (in Russian)]

[4] Моэно Н. Наука о льде. М.: Мир, 1988, 231 с. [Moeno N. The science of ice, Moscow, Mir, 1988, 231 p. (in Russian)] 